\title{
Design and Development of Agricultural Spraying Drone: Frame and Analysis
}

\author{
Shantanu D. Munghate ${ }^{1} \mid$ Dr. Prashant S. Kadu ${ }^{1}$ \\ ${ }^{1}$ Department of Mechanical Engineering, AGPCE Nagpur, Nagpur, Maharashtra, India
}

To Cite this Article

Shantanu D. Munghate and Dr. Prashant S. Kadu, "Design and Development of Agricultural Spraying Drone: Frame and Analysis", International Journal for Modern Trends in Science and Technology, 6(8): 261-270, 2020.

Article Info

Received on 26-July-2020, Revised on 09-August-2020, Accepted on 12-August-2020, Published on 21-August-2020.

\section{ABSTRACT}

Drone design for spraying requires several concerns one of which is designing the frame. Right from selecting the right component to the Analysis of design are the crucial steps in design. This paper focuses on mechanical design of octacopter frame for the spraying operation with future modifications in consideration. Selection of components is done according to the $3 \mathrm{lt}$. fluid payload with tank while the thrust to weight ratio in selection is kept 3:1. The drone is designed in CATIA V5 while the analysis results are obtained in ANSYS 19.2. In Analysis results of CFD, Structural and Explicit Dynamics the design was found to be optimum.

KEYWORDS: UAV, Drone, Spraying, Frame, CFD

\section{INTRODUCTION}

The design for drone assembly for the spraying operation involves the crucial part of drone design. This is the $3^{\text {rd }}$ paper in the series of Design and Development of Agricultural Spraying Drone. The common structure of any drone involves frame, propellers, motors, control assembly (including flight controller, transmitter and receiver and electronic speed controller), landing gear, electronic sensors and circuits with positioning capabilities.

The aspects of design of frame include structural and aerodynamic optimality i.e. the frame should be structurally strong and should have minimum possible drag. Considering both the scenario a suitable combination of both of these is obtained for design. The selection of circular section for arm design is made as a part of this paper the section being relatively easy to manufacture and has a relative advantage over the drag to lift ratio of most commonly used section and it provides the sufficient strength for the design. A carbon fiber composite is selected as the material for the frame of the drone under the $1^{\text {st }}$ paper in the series after reviewing the literature.

The CAD model is designed in CATIA V5 while the Analysis was carried out in ANSYS 19.2 in different modules including static structural, Explicit Dynamics and Fluent

\section{LITERATURE REVIEW}

Wen, S. et al (2019) [1]Author used quadcopter M234-AT plant protection drone. Weight of the drone without battery is $12.1 \mathrm{~kg}$. Quadcopter contains 2 blades per rotor with rotor diameter of $766 \mathrm{~mm}$. Frame length is $1156 \mathrm{~mm}$ and space in between adjacent rotors is $925 \mathrm{~mm}$.

Yallappa D. et al(2017) [2] : The author has used a hexacopter aluminium frame for a weight of $5 \mathrm{~kg}$ with two 6 cells LiPo batterie. s. Aluminium frames were used with glass fibre airframe arm mounts to support the thrust of the motor. Aluminium pipes were also used to make the supporting frame for the tank. 
P,V.S.R. et al 2019[3] This paper deals with the design of UAV for agriculture spraying. The frame consists of aluminium while the hardware includes a $360 \mathrm{kv}$ motor (45A ESC) coupled with $14 \times 4.7$ propeller, pixhawk 2.4.8 Flight controller and powered with $3300 \mathrm{mAh} 6 \mathrm{~S}$ LiPo battery. Total weight of the assembly including the supporting weight of hardware was $4.7 \mathrm{~kg}$. According to the author the design had $4.8 \mathrm{Kg}$ lift capacity with 1.8 Kg payload capacity.

Vihari, M. M.2018[4] The author proposed an IoT based UAV for agricultural spraying. The weight of payload i.e. the weight of sprayer with all the sprayer related component was $1300 \mathrm{~g}$. The selected ratio of thrust to weight was $2: 1$. After the calculations an estimated thrust of $3100 \mathrm{~g}(755 \mathrm{~g}$ thrust per motor) was selected for hovering. A 1000 $\mathrm{KV}$ motor with $10 \times 4.5$ propellers were selected for accomplishing the thrust.

I D Pharne et al 2018 [5] The author made an attempt to design an agriculture drone with ATmega328 Microprocessor and 3000mAh 25C BLDC motor and a $3.7 \mathrm{~V}$ 3SP1 3 cells battery. The Frame was made up of glass fiber. The author used Arduino with Multi wii open source for the design.

Karan Kumar Shaw et al (2020) [6] In this paper the author has designed a drone for spraying. Carbon fiber was used as the material of the frame which were basically $492 \mathrm{~mm}$ long hollow pipes per arm. The drone weighed about $5946 \mathrm{~g}$ and a payload weighing about 6750 grams. The motors were able to provide a thrust of $38.2 \mathrm{~kg}(3.01: 1$ Thrust to weight ratio) at $100 \%$ throttle powered with a $22000 \mathrm{mAh} 22.2 \mathrm{~V}$ LiPo battery with an endurance time $10.42 \min .45 \mathrm{~cm}$ from each other.

Rahul Desale et al 2019 [7] The author has selected the components for the design of UAV. The components include The light weight PVC pipe frame, a $1000 \mathrm{kv}$ BLDC motor (980 g Thrust), 30A ESC, 9" propellers, 6500 mAh battery, KK 2.1.5 flight controller, Radio controller and receiver, nozzles and a 9V submersible Pump. The author advocates use 2:1 thrust to weight ratio for the design..

Vikrant Krishna Suryawanshi et al [8] The author made an attempt to design a drone to carry the payload up to $3 \mathrm{Kg}$ using an Aluminium frame for fertilizer spraying. The author used $5500 \mathrm{mAh} 3$ cells LiPo battery, Pixhawk 2.4.8 Flight controller, Avionic RCB OS-10 Transmitter and receiver, a 910 KV motor (1050 g Thrust), $12 \mathrm{~V}$ ESCs and $12 \mathrm{~V}$ DC motor pump.
Boguslawa Berner et al (2018) [9] The author used DJI 4114, 400kV electric motor and $15 \times 2.2$ dimensions of propeller. The drone was mounted to the trolley with the frame speed of $1.2 \mathrm{~m} / \mathrm{s}$ while the motor rotation speed was $50 \mathrm{rad} / \mathrm{s}$.

Weicai Qin et al [10]The author has used triadimefon SC (44\%) for the plant height of 0.8-10 $\mathrm{m}$ in height and spaced by $10 \mathrm{~cm} \times 20 \mathrm{~cm}$. The comparision was done with chienese knapsack sprayer.

S.Meivel M.E. et al (2016) [11]This paper deals with the design of the UAV Spraying System. The Quadcopter consists of four rotor propellers with controller. The main part of this vehicle is the flight controller.To create the differential thrust as well the quadcopter hover the four rotors are used here too they are move accordance with the rotors speed.In quadcopter construction Plus configuration and Cross configuration are used too; here we are using Cross Configuration hence, it is easier than Plus Configuration. $4.4 \mathrm{~kg}$ is the total weight to be lifted; as well $8 \mathrm{~kg}$ is the total thrust to be produced. Tot navigate the UAV, GPS guidance system is used here.

Dr.R.Athilingam et al 2019[12] Author aimed to design paper that the drone contains four wings containing fins and blades, which is useful to lift and to vary the speed of the rotors by operating the radio controller. This Radio Controller is properly equipped with a micro controller to avoid the obstacles of sensors and varying speed $f$ the rotatry wings and the ATMEGA/ARDUINO software programming is compatible with the rotatry wings. Estimation of aircraft weight is taken here and too of DC motor ; conventional propellers can be determined.

Parthasarathy Garre et al2018 [13] In this paper Autonomous spraying of pesticides examination is explained. The used flight controller is Pixhawk STM32F427 with $168 \mathrm{MHz}$, RAM of KB 256, Flash of MB 2, bit 32 processor. Two sensors with 14 bit accelerometer and 16 bit gyroscope as MPU6000 and barometer MEAS is used here. BLDC is used is used to run the motor ESC is used for controlling. Transmissions are received by radio controller. The Li-Po battery is used to supply the power.

\section{STRUCTURAL ANd CFD ANALYSis:}

The structural analysis is usually based on Hooke's Law and compatibility equations (strain displacement relations) while the CFD analysis is performed using the conservation equations which include mass conservation (continuity equation), Momentum Conservation (Navier-Stokes equation) 
and energy conservation (Bernoulli's equation). A usual procedure to use a tool (here ANSYS 19.2) for solving these equations using the finite element method (structural Analysis) and Finite Volume Method (CFD Analysis). The analysis tools follow the following procedure:

A: Pre-Processing:

1. User Input: The user input involves importing the solid geometry, establishing the boundary conditions and loading conditions. In CFD, the fluid properties as well as the solver domain and initial conditions along with the boundary conditions required for the solver to establish the solution are required as user input. Also, the physical and structural properties of the selected geometry shall be applied to the geometric model.

2. Numerical Solution: This process involves the process of discretization i.e. dividing a model into several tiny elements or cells and a numerical method calculates the required result based on the mathematical model. The element or cell quality and quantity decide the quality of solution as well as computational time and resources required.

3. Determination of Mathematical Model: The mathematical model used in the structural analysis usually uses the Hooke's Law and Strain-Displacement relations and using these relations a matrix is form for an element which is then iteratively solved in solver.

\section{B. Processing/Solving:}

The analysis tool calculates the solution based on user input for which it establishes a mathematical model. In a nutshell it can be said that the solver solves mathematical model instead of solving the physical problem and hence careful modelling and pre-processing is essential for a quality solution. In finite element method the generated nodes serve as the connection between subsequent elements which are utilized to further the solution from element to element. The CFD method uses the cell center values and nodes the find out the solution for a particular cell and it is later propagated over other cells in connection.

C. Post-Processing and Validation:

Post processing involves selecting the variables which are required as a solution. The solution can be obtained in different forms including numerical value, graphical forms, colored bands and contours over the domain of geometric model. The post-processing is also used in validating the solution. acceptability of discretization error, approximations and assumptions used by model and are used to enhance the solution. When the solution has a level of unacceptability in the error and differences in the experimental results and expected trends, the solution is reiterated by modifying the boundary conditions, refining the discretization and improving the model. The expected trends of solution and experimental results are used in validating the results obtained from the analysis.

Mathematical Model for structural analysis:

Selection of mathematical model is an essential step considering the proper modelling. The mathematical model of the structural analysis involves the following equations based on which the solution is calculated.

Force Balance:

The force balance represents the balance of all the forces that are applied on the body which in turn generates the stresses in the body. In static structural analysis it helps in finding out the balance between the forces which is the preliminary condition for carrying out static structural analysis. The force balance includes the normal stresses in $\mathrm{X}, \mathrm{Y}$ and $\mathrm{Z}$ direction, the shear stress in $\mathrm{XY}, \mathrm{YZ}$ and $\mathrm{XZ}$ planes and the body force in $\mathrm{X}, \mathrm{Y}$ and $\mathrm{Z}$ direction.

$$
\begin{gathered}
\frac{\partial \sigma_{x}}{\partial x}+\frac{\partial \tau_{x y}}{\partial y}+\frac{\partial \tau_{x z}}{\partial z}+\mathrm{f}_{x}=0 ; \frac{\partial \tau_{x y}}{\partial x}+\frac{\partial \sigma_{y}}{\partial y}+\frac{\partial \tau_{y z}}{\partial z}+\mathrm{f}_{y}=0 \\
\frac{\partial \tau_{x z}}{\partial x}+\frac{\partial \tau_{y z}}{\partial y}+\frac{\partial \sigma_{z}}{\partial z}+\mathrm{f}_{z}=0
\end{gathered}
$$

3D-Hooke's Law:

The 3-Dimensional Hooke's Law is the relation between stresses, strain and elastic constants in all the 3 directions and planes. This generalized Hooke's Law is used in determining the stresses and strains with the input as the elastic constant and boundary conditions.

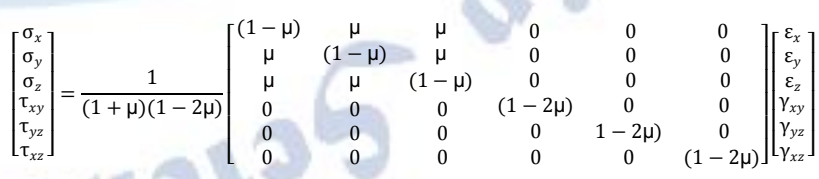

Strain-Displacement Relations:

The Hooke's Law is insufficient in finding all the variables that are to be calculated. Hence the strain-displacement relations also known as the compatibility equations are used in determining such variables.

$$
\varepsilon_{x}=\frac{\partial v}{\partial x} ; \varepsilon_{y}=\frac{\partial v}{\partial y} ; \varepsilon_{y}=\frac{\partial \omega}{\partial z}
$$




$$
\gamma_{x y}=\frac{\partial v}{\partial x}+\frac{\partial v}{\partial y} ; \gamma_{y z}=\frac{\partial \omega}{\partial y}+\frac{\partial v}{\partial z} ; \gamma_{x z}=\frac{\partial \omega}{\partial x}+\frac{\partial v}{\partial z}
$$

Computational Fluid Dynamics:

CFD involves calculation of fluid and fluid forces-based variables utilizing the three conservation equations of mass, momentum and energy. The finite volume method is usually applied for calculating these variables. These variables yield the solution required based on the model used.

Continuity Equation (Conservation of Mass):

The infamous continuity equation involves conservation of mass. The continuity equation states that the mass is conserved i.e. the amount of mass entering a system must be equal to the amount of mass leaving the system when there is no accumulation of mass.

$$
\rho \frac{D \rho}{D t}+\rho \nabla \cdot \overline{\mathrm{v}}=0
$$

\section{Navier-Stokes}

Equation (Conservation

of

Momentum):

The Navier-Stokes equation represents the conservation of momentum. Balancing the pressure, gravity and viscous fluid forces against the inertia force of the fluid which is the product of mass and acceleration of the fluid.

$$
\rho \frac{D \bar{v}}{D t}=-\nabla \overline{\mathrm{p}}+\rho \bar{g}+? \nabla^{2} \bar{v}
$$

Reynolds Average Navier-Stokes Equation (RANS):

In RANS, the turbulent flows are described using the Reynolds Decomposition. In Reynolds Decomposition the instantaneous velocity is decomposed into the average velocity and its fluctuation $\left(u_{\text {inst. }}=u+u\right.$ '). These fluctuations give rise to the Reynolds Stress $\left(-\rho u^{\prime} u_{j}^{\prime}\right)$, this stress exists due to exchange of momentum in turbulent eddies. This stress is nonlinear and needs an extra model to assist in completing this equation, these models are known as turbulence models.

$$
\begin{aligned}
& \rho \frac{D \bar{u}}{D t}=-\frac{\partial p_{x}}{\partial x}+\frac{\partial \partial}{x}\left(\left[\frac{\partial \bar{u}}{\partial x}-\rho \overline{u^{\prime 2}}\right)+\frac{\partial \partial}{y}\left(\left[\frac{\partial \bar{u}}{\partial y}-\rho \overline{u^{\prime} v}\right)+\frac{\partial \partial}{z}\left(\text { 回 } \frac{\partial \bar{u}}{\partial z}-\rho \overline{u^{\prime} w^{\prime}}\right)\right.\right. \\
& \rho \frac{D \overline{\mathrm{v}}}{D t}=-\frac{\partial p_{y}}{\partial y}+\frac{\partial \partial}{x}\left(\mathrm{Q} \frac{\partial \overline{\mathrm{v}}}{\partial x}-\rho \overline{u^{\prime} v^{\prime}}\right)+\frac{\partial \partial}{y}\left(\mathrm{Q} \frac{\partial \overline{\mathrm{v}}}{\partial y}-\rho \overline{v^{\prime 2}}\right)+\frac{\partial \partial}{z}\left(\mathrm{Q} \frac{\partial \overline{\mathrm{v}}}{\partial z}-\rho \overline{v^{\prime} w^{\prime}}\right) \\
& \rho \frac{D \overline{\mathrm{u}}}{D t}=-\frac{\partial p_{z}}{\partial z}+\rho \overline{g_{z}}+\frac{\partial \partial}{x}\left(\left[\frac{\partial \overline{\mathrm{u}}}{\partial x}-\rho \overline{u^{\prime} w^{\prime}}\right)+\frac{\partial \partial}{y}\left(\overline{\mathrm{g}} \frac{\partial \overline{\mathrm{u}}}{\partial y}-\rho \overline{v^{\prime} w}\right)+\frac{\partial \partial}{z}\left(\mathrm{Q} \frac{\partial \overline{\mathrm{u}}}{\partial z}-\right.\right.
\end{aligned}
$$

$\mathrm{k}-\varepsilon$ turbulence model:

This turbulence model uses two transport equations in the form of two transport variables called turbulent kinetic energy $(\mathrm{k})$ and rate of dissipation of turbulent kinetic energy $(\varepsilon)$. Here, ? $t_{t}$ is the Eddy Viscosity, this eddy viscosity is not a material property but it is calculated in terms of $\mathrm{k}$ and $\varepsilon$. The turbulent kinetic energy $(\mathrm{k})$ represents the measure of energy contained in fluctuations while the rate of dissipation of turbulent kinetic energy $(\varepsilon)$ represents the rate of dissipation of such energy.

$$
\begin{gathered}
\frac{D k}{D t}=\frac{\partial \partial}{x_{j}}\left(\frac{Q_{t}}{\sigma_{k}} \frac{\partial \mathrm{k}}{\partial x_{j}}\right)+P_{k}-\varepsilon \\
\frac{D \varepsilon}{D t}=\frac{\partial \partial}{x_{j}}\left(\frac{\overbrace{t}}{\sigma_{\varepsilon}} \frac{\partial \varepsilon}{\partial x_{j}}\right)+C_{\varepsilon 1} \frac{\varepsilon}{k} P_{k}-C_{\varepsilon 2} \frac{\varepsilon^{2}}{k} \\
?_{t}=C \frac{\mathrm{k}^{2}}{\varepsilon} \\
P_{k}=\frac{1}{2} \text { 国 }_{t}\left(\frac{\partial \overline{u_{i}}}{\partial x_{j}}+\frac{\partial \overline{u_{j}}}{\partial x_{i}}\right)^{2}
\end{gathered}
$$

Energy Equation (Conservation of Energy):

This equation represents the conservation of fluid as well as thermal energy. This conservation equation involves changes in Heat flux, Convection term, Pressure Work, local energy change with time and irreversible transfer of mechanical energy. Since the analysis doesn't involve fluctuation of thermal energy the thermal energy and the fluctuation is negligible in the process.

$$
\begin{gathered}
\frac{\partial(\rho E)}{\partial t}-r_{E}-\frac{h}{2} \frac{\partial \partial}{x_{i}}\left(\frac{\partial(\rho E)}{\partial t}-r_{E}\right)=0 \\
r_{E}=-\frac{\partial \partial}{x_{i}}(\rho E+\rho)+\frac{\partial \partial}{x_{i}}\left(k \frac{\partial T}{\partial x_{i}}+u_{i} \text { ? } \frac{\partial u_{i}}{\partial x_{i}}\right)+Q
\end{gathered}
$$

The total energy, $\mathrm{E}$ i.e. the sum of thermal and kinetic energy is given by

$$
E=C_{\mathrm{v}} T+\frac{1}{2} u_{i}^{2}
$$

\section{FRAME DESIGN}

\section{Payload Estimation:}

It is desired to spray the spraying liquid of 3 liters per flight. Hence it is required by the tank to hold weight of 3 liters along with the weight of tank as payload.

Payload weight $=$ density $\times$ volume $=1000 * 3=3 \mathrm{~kg}$ For primary estimation of weight, a 3 liters tank with $10 \mathrm{~mm}$ thickness consists of ABS. An estimated weight of the tank is considered to be $300 \mathrm{~g}$. While the pump required for generating the pressure for spraying weighs 600 grams and 4 nozzles weighing $7 \mathrm{~g}$ each. While rest of required assembly has an estimated weight of 400 grams. The payload weight is estimated to be $4328 \mathrm{~g}$ $(3000+300+600+4 \times 7+400)$. To find out the necessary component, the required iterations were carried out using the following flow chart.

The adopted procedure follows the flow chart in which

\section{Selection of Propulsion System:}

1. Motor: Motor is the means of motion for the drone assembly. The motors usually selected are 
BLDC motors. The brushless motors are advantageous since the brushes are absent in the design that eliminates the requirement of replacement of brushes and minimizes the requirement of maintenance. The motors are generally designated on the basis of their stator diameter and height. The taller stator provides relatively more power and higher RPM. Similarly, wider stator provides more torque at lower RPM. Proper selection of motor depending upon their KV rating and thrust is an essential step. The KV rating is RPM generated by the motor per volt. While the thrust is the force which propels the drone in the air. Usually manufacturer manuals contain the information regarding the specifications of the motor including the required compatible hardware.

The selected motor is T-motor V605 KV120. The highest amount of thrust generated by the motor at $100 \%$ throttle is 12761 grams at 7036 RPM. While the recommended hardware includes a $12 \mathrm{~S}$ battery, an 80A ESC and a 2274 propeller. The selected motor is more than sufficient to generate the required thrust for the motion of the assembly while it also provides an opportunity to modify design according to the modified payload.

2.Propeller: The Propeller is responsible generating the required lift in order to obtain the thrust for the propulsion. Some of the theories explaining the lift generated by propeller are Bernoulli's equation, Newtons 2nd Law and Coanda effect. While the theories are explaining the generated lift, they fail to explain the different phenomenon and exceptions related to it. The propellers can be made up of two or more blades. The longer the blade is more is the moment of inertia i.e., the efforts required to generate and maintain the rotation while more numbers of blades increase the mass also requiring more rotations. Hence it is required to find the balance between both.

The selected propeller is T-motor V22x7.4" propeller which has 22-inch diameter and 7.5-inch pitch.

\section{Selection of Power:}

selection of power source is a critical selection since the power source which is mostly a LiPo batteries in the case of multirotor drones make up to $20-60 \%$ of entire weight of the assembly. A high discharge (depends on $\mathrm{C}$ rating) and high capacity ( $\mathrm{mAh}$ rating) battery provides better performance and flight time. The power source selection is affected by the weight of the drone and current drawn by electronics component which is mostly affected by current draw of the motor.

\section{Flight Controller and Control System:}

The flight controller is the brain of the drone and the selection is based mainly on its processor speed, No. of UART and available flash memory along with the features such as automation. The flight controller selection is crucial and it must be ensured that there are required amount of ports available on the flight controller for connecting the accessories. The IMU (inertia measurement unit) usually consists of accelerometer, barometer, magnetometer and gyroscope and generally assisted by GPS is responsible for motion resolution and precision. Hence a flight controller must be chosen in such a way that is encompasses all the required feature.

The control is usually achieved by transmitter-receiver circuits with receiver placed on the drone and transmitter circuit present in control assembly near the pilot. When the receiver receives the signal, the signal is transmitted to the flight controller for further action. This control by flight control is achieved with the help of ESC and assisting sensors such as obstacle detection sensor, barometer and sonar sensor.

\section{ESC(Electronic Speed Controller):}

The Electronic Speed Controller as the name indicates is a speed regulating circuit based on diodes, rectifiers and other electronic drives. They reduce or increase the amount of current flow as instructed by flight controller and hence they achieve speed control. ESCs are crucial in performing roll, pitch, yaw and other motions related to drones. The ESCs are usually recommended by the motor manufacturer according to their ampere rating.

\section{Selection of Support Structure:}

Frame and Landing Gear: The frame is designed based on strength it required to carry out required operation also based on the propeller spacing. The propellers should be placed at a sufficient distance in order to avoid the interference and influence of propellers downwash on the frame and the neighboring propeller. The frame length is chosen according to the propellers spacing also a care should be taken that the frame structure should be structurally and aerodynamically optimal. The landing gear is the support structure for drone frame which provides proper landing and takeoff. The frame supports stresses while the landing gear supports the weight of the assembly. These support structures should be tested for impact conditions and structural loads.

Weight Estimation: 
The weight is estimated on the basis of selected components. The component selection is done using the procedure enlisted in the flowchart.

Table 4.1 Selected Component

\begin{tabular}{|c|c|c|}
\hline Component & $\begin{array}{c}\text { No. of } \\
\text { Components }\end{array}$ & $\begin{array}{c}\text { Aggregate } \\
\text { Weight (in } \\
\text { grams) }\end{array}$ \\
\hline Payload & - & 4328 \\
\hline $\begin{array}{c}\text { Frame and } \\
\text { Landing-Gear } \\
\text { (Estimated) }\end{array}$ & - & 1000 \\
\hline $\begin{array}{c}\text { T-motor } \\
\text { V605 KV210 }\end{array}$ & 8 & 2560 \\
\hline $\begin{array}{c}\text { T-motor } \\
\text { V22x7.4 } \\
\text { Propellers }\end{array}$ & 8 & 384 \\
\hline $\begin{array}{c}\text { ESC FLAME } \\
80 A \text { HV }\end{array}$ & 8 & 848 \\
\hline $\begin{array}{c}12 \text { S LiPo } \\
\text { Battery }\end{array}$ & 1 & 4010 \\
\hline $\begin{array}{c}\text { Pixhawk } \\
\text { Flight } \\
\text { Controller }\end{array}$ & 1 & 15.8 \\
\hline $\begin{array}{c}\text { Electronics } \\
\text { Components. } \\
\text { Sensors and } \\
\text { Wires }\end{array}$ & - & 800 \\
\hline $\begin{array}{l}\text { Total } \\
\text { Weight }\end{array}$ & 13945.8 \\
\hline
\end{tabular}

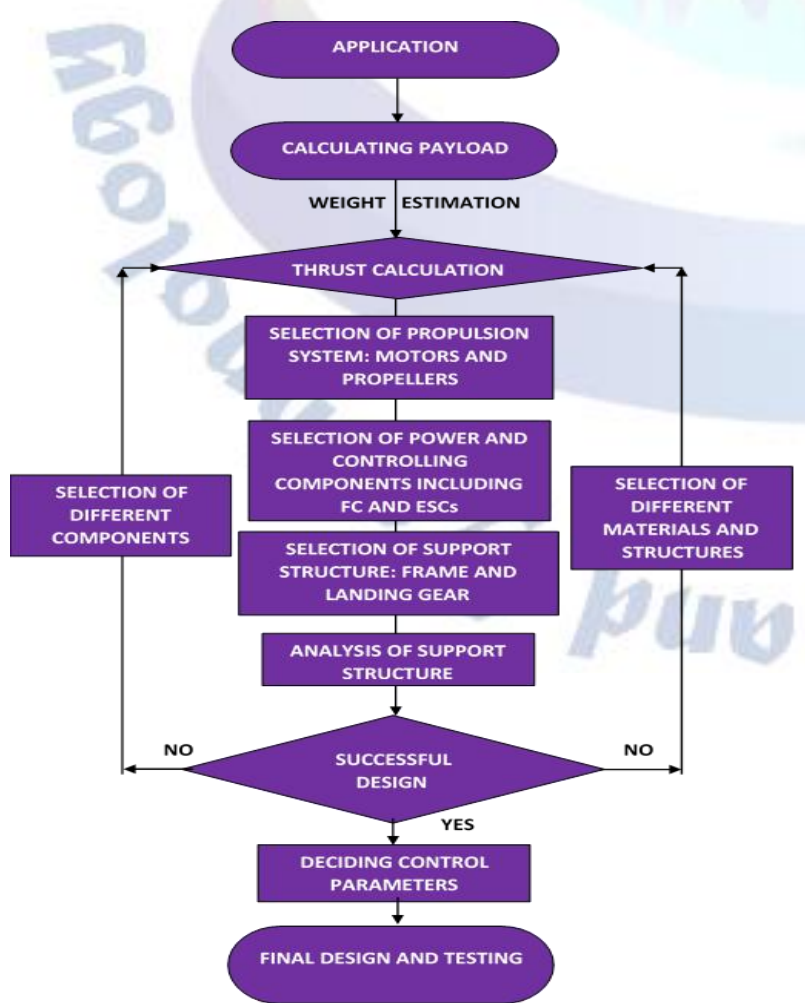

Fig 4. 1 Component Selection Method

\section{Frame design Calculation}

A. Material for the Frame:

Carbon fiber composites are common in aerospace and aeronautical structures. These fibers and embedded into polymeric matrix to enhance their shear strength. Hextow IM-7 is selected for this particular analysis. It is commonly used in aerospace industry. [14] It is a PAN based fiber with higher tensile strength with good shear strength and low density. [15].

Table 5.1 Material Properties

\begin{tabular}{|l|c|l|c|}
\hline \multicolumn{4}{|c|}{ HexTow IM7 Carbon Fiber Epoxy Composite } \\
\hline Properties & Values & $\begin{array}{l}\text { Poisson's } \\
\text { Ratio }\end{array}$ & 0.3 \\
\hline $\begin{array}{l}\text { Tensile } \\
\text { Strength } \\
\text { (MPa) }\end{array}$ & 2723 & $\begin{array}{l}\text { Compressive } \\
\text { Modulus } \\
\text { (GPa) }\end{array}$ & 150 \\
\hline $\begin{array}{l}\text { Tensile } \\
\text { Modulus } \\
\text { (GPa) }\end{array}$ & 164 & $\begin{array}{l}\text { Flexural } \\
\text { Strength } \\
\text { (MPa) }\end{array}$ & 1862 \\
\hline $\begin{array}{l}\text { Tensile } \\
\text { Strain (\%) }\end{array}$ & 1.6 & $\begin{array}{l}\text { Shear } \\
\text { Strength } \\
(\mathrm{MPa})\end{array}$ & 128 \\
\hline $\begin{array}{l}\text { Compressive } \\
\text { Strength } \\
\text { (MPa) }\end{array}$ & 1689 & $\begin{array}{l}\text { Density } \\
\left(\mathrm{Kg} / \mathrm{m}^{3}\right)\end{array}$ & 1780 \\
\hline
\end{tabular}

For this particular analysis the use of solid section is considered. Use of solid section in the frame instead of the hollow one since in bending maximum stress is observed at the periphery of the section in order to this the diameter and thickness is needed to be increased which results into heavier hollow section as well as increase in overall surface area which increases the drag on the frame. Hence a solid circular section is considered for designing the drone frame.

\section{B. Strength Criterion:}

Maximum Shear Stress induced,

$$
\left(\tau_{\max }\right)=\frac{\mathrm{F}_{\max } \mathrm{Q}_{\max }}{y \mathrm{I}_{N . A .}}=\frac{4 \times \mathrm{F}_{\max }}{3 \times \Pi \times \frac{d^{2}}{4}}
$$

Diameter at which the beam will fail is

$$
d=\sqrt{\frac{16 \times 17.17}{3 \pi \times 128 \times 10^{6}}}=0.00047 \mathrm{~m}
$$

Maximum Bending Stress induced,

From the Bending equation,

$$
\begin{gathered}
\frac{\sigma_{b, \max }}{\mathrm{y}}=\frac{\mathrm{M}_{\max }}{\mathrm{I}_{N \cdot A .}} \\
\sigma_{b, \max }=\frac{\mathrm{M}_{\max }}{\Pi \mathrm{x} \frac{d^{4}}{64}} \frac{d}{2}
\end{gathered}
$$




$$
d=\sqrt[3]{\frac{64 \times 13.73}{\pi \times 1862 \times 10^{6}}}=0.005316 \mathrm{~m}
$$

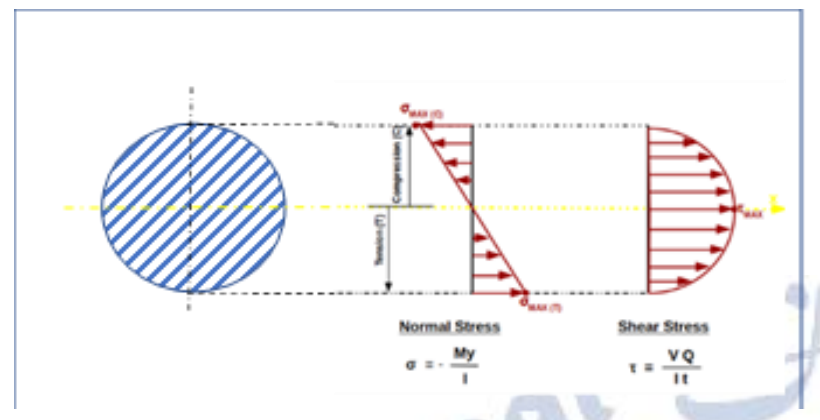

Fig 5. 1 Stress Distribution

C. Rigidity Criterion:

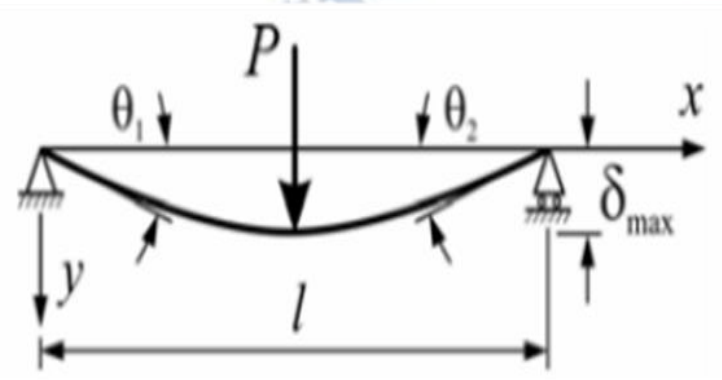

Fig 5.2 Deflection of Simply Supported Beam With Central Load Ultimate elongation at failure is given as $1.9 \%$ which can be converted into the deflection using the relation between slope and deflection.

$$
\begin{gathered}
\text { Maximum Slope }=\tan (\theta)=\frac{\left(\delta_{\max }\right)}{l / 2} \\
(\theta)=\cos ^{-1}\left(\frac{0.8}{0.8+0.019 \times 0.8}\right)=\cos ^{-1}(0.9813)=11.08^{\circ} \\
\left(\delta_{\text {max }}\right)=0.8 \times \tan \left(11.08^{\circ}\right)=0.1566 \mathrm{~m} \\
\left(\delta_{\text {max }}\right)=\frac{\mathrm{Pl}^{3}}{48 E I}=\frac{\mathrm{Pl}^{3}}{48 E \times \Pi \times \frac{d^{4}}{64}} \\
d=\sqrt[4]{\frac{64 \times 34.335 \times 1.6^{3}}{48 \times \text { п х } 164 \times 10^{9} \times 0.1566}}=0.00694 \mathrm{~m}
\end{gathered}
$$

After calculating the diameter using both criterion an estimated diameter of $0.00694 \mathrm{~m}$ is found to be the minimum diameter required to avoid failure for the selected material. Hence after careful consideration, five times the diameter has been selected for the drone frame which is $0.0347 \mathrm{~m} \approx$ $0.035 \mathrm{~m}$.
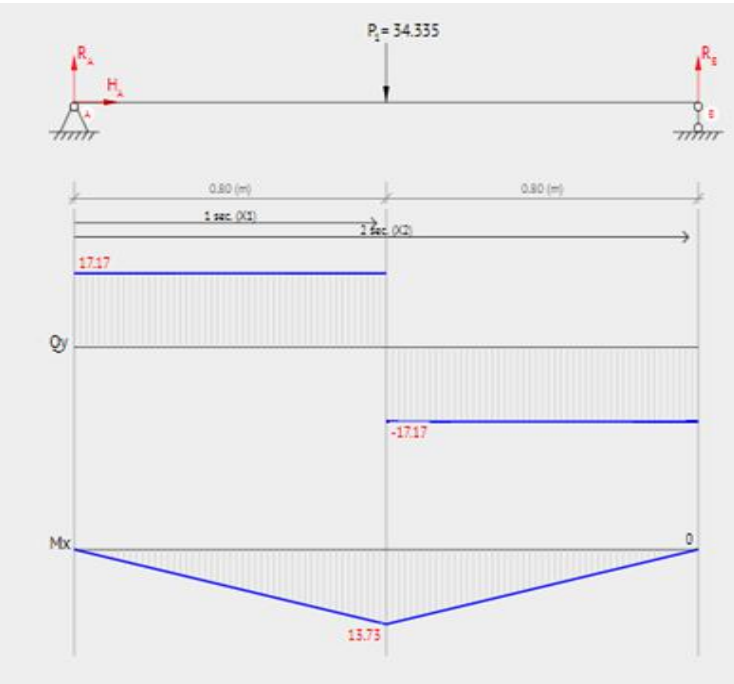

Fig 5. 3 SFD BMD Analysis

VI. STRUCtURAL ANALYSis

The structural analysis is conducted in ANSYS 19.2 Static Structural. The boundary conditions applied were the thrust force at each motor and the weight was made to act through the center of gravity. The load of $32.14 \mathrm{~N}$ was applied at the motor end while the total weight of $257.1 \mathrm{~N}$ was made to act through the center of gravity. After meshing and solving process the results were obtained in four parameters viz. Equivalent Strain, Equivalent Stress, Maximum Shear Stress and Total Deformation.

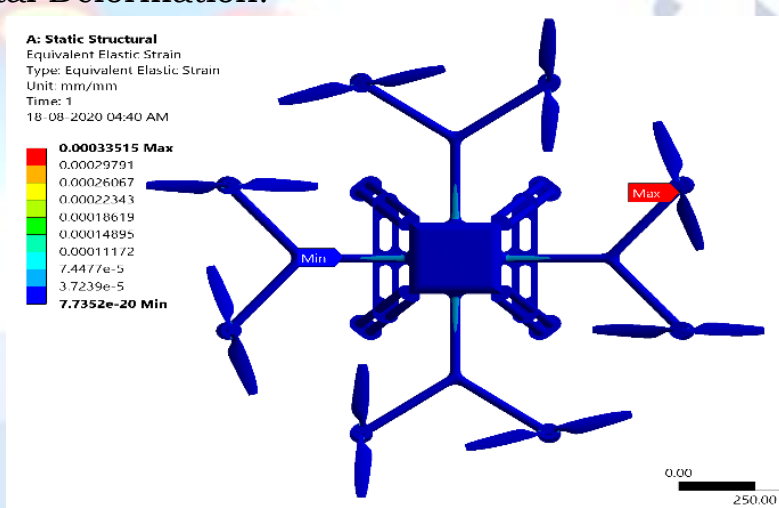

Fig 6. 1 Equivalent Elastic Strain

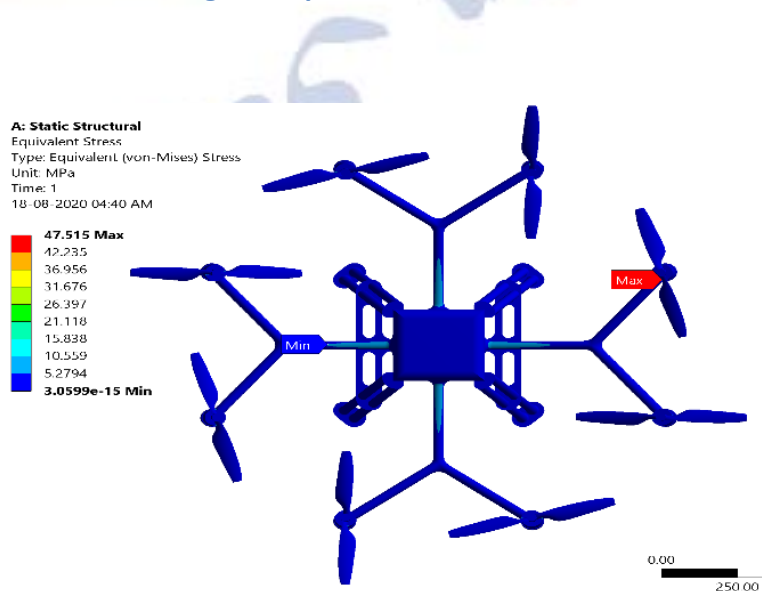

Fig 6. 2 Equivalent Stress 


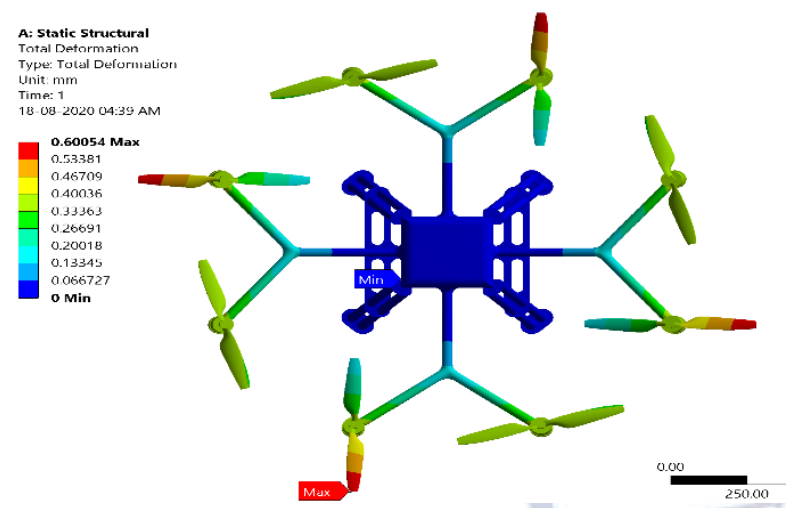

Fig 6. 3 Total Deformation

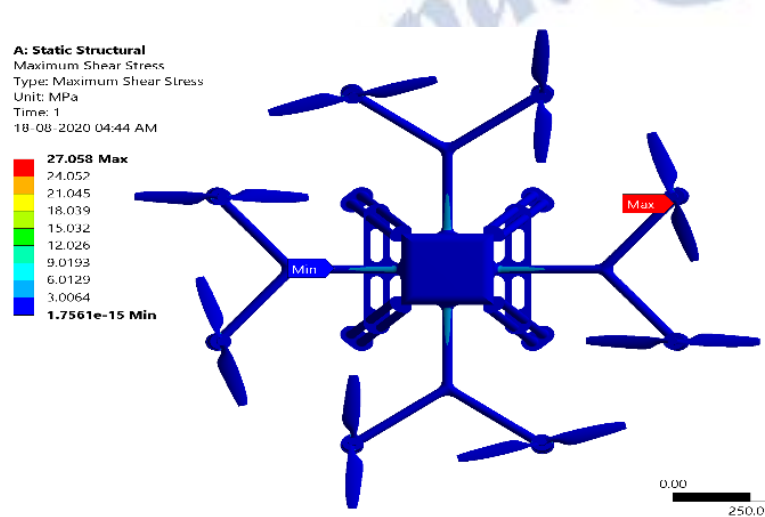

Fig 6. 4 Maximum Shear Stress

Table 6.1 Structural Analysis Results

\begin{tabular}{|c|c|c|}
\hline \multirow{3}{*}{$\begin{array}{l}\text { Equivalent } \\
\text { Elastic } \\
\text { Strain }(\mathrm{mm} / \mathrm{mm})\end{array}$} & Min & $7.7352 e-20$ \\
\hline & $A v g$ & $3.1305 e-06$ \\
\hline & $\operatorname{Max}$ & $3.351 e-04$ \\
\hline \multirow{3}{*}{$\begin{array}{l}\text { Equivalent } \\
\text { Elastic } \\
\text { Stress }(\mathrm{MPa})\end{array}$} & Min & $3.0599 e-15$ \\
\hline & $A v g$ & 0.49812 \\
\hline & $\operatorname{Max}$ & 47.515 \\
\hline \multirow{3}{*}{$\begin{array}{l}\text { Total } \\
\text { Deformation } \\
(\mathrm{mm})\end{array}$} & Min & 0 \\
\hline & $A v g$ & 0.12049 \\
\hline & $\operatorname{Max}$ & 0.60054 \\
\hline \multirow{3}{*}{$\begin{array}{l}\text { Maximum } \\
\text { Shear Stress } \\
(M P a)\end{array}$} & Min & $1.7561 e-15$ \\
\hline & $A v g$ & 0.2544 \\
\hline & $\operatorname{Max}$ & 27.058 \\
\hline
\end{tabular}

\section{CFD ANALYSIS}

Calculations for Reynolds Number:

The Reynolds Number for an airfoil can predict the flow pattern for an entire system since the lift required for the drones are generated by the propellers and the flow around propellers can be used to model the flow around the drone. The chord of the airfoil is treated as the characteristic length in the Reynolds Number formula while the speed is calculated at the $3 / 4^{\text {th }}$ of diameter of the propeller. The average speed of motor and propeller at $100 \%$ throttle is 7036 RPM the Chord length is $23.96 \mathrm{~mm}$. The average temperature of Vidarbha region for the yield season is $27^{\circ} \mathrm{C}$, the density of air at this particular temperature is $1.174 \mathrm{~kg} / \mathrm{m}^{3}$ and dynamic viscosity is $1.806 \times 10^{-5} \mathrm{~kg} / \mathrm{m}-\mathrm{s}$.

$$
\begin{aligned}
& v=\frac{\Pi D N}{60}=\frac{3.14 \times 0.419 \times 7036}{60}=154.40 \mathrm{~m} / \mathrm{s} \\
& R e=\frac{\rho v L}{\square}=\frac{1.174 \times 154.40 \times 0.02396}{1.806 \times 10-5}=240483
\end{aligned}
$$

Hence the flow can be declared as turbulent.

The CFD Analysis was conducted in ANSYS 19.2 Fluent where the drone assembly was aerodynamically analyzed against the air speed of $6.33 \mathrm{~m} / \mathrm{s}$ which is the relative speed between the air and the drone. The effect of the air on the drone in forward pitch motion was selected for analysis since it is the motion which will be used by the drone for almost $80 \%$ of the time in a normal spraying operation.

The dynamic pressure is used to define the drag and lift coefficient where the drag coefficient shows the effect of aerodynamic forces over drone. The flow accelerates around the circular section and at the same sections the wall shear stress is more. The distribution of dynamic pressure shows the less pronounced of the drag and lift over the drone frame.

Table 7.1 Effect of air on the Drone Frame

\begin{tabular}{|l|l|}
\hline Lift force & 1.2976 \\
\hline Drag force & 3.4010 \\
\hline Lift coefficient & $5.5169 \mathrm{e}-02$ \\
\hline Drag coefficient & $2.1069 \mathrm{e}-01$ \\
\hline
\end{tabular}

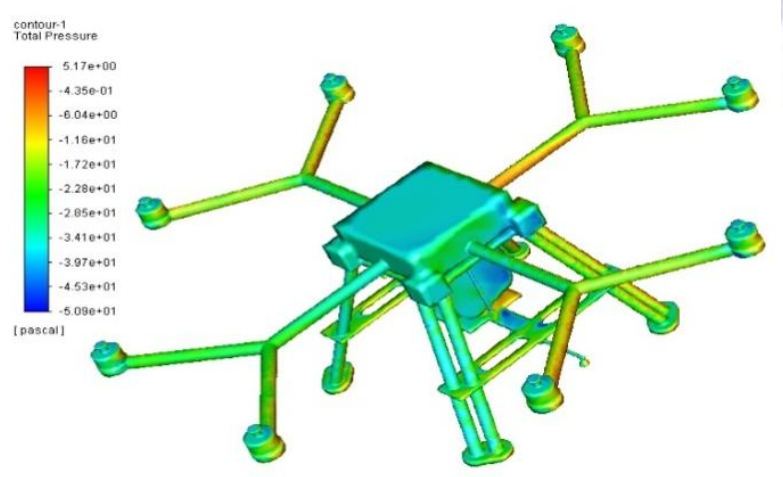

Fig 7. 1 Total Pressure

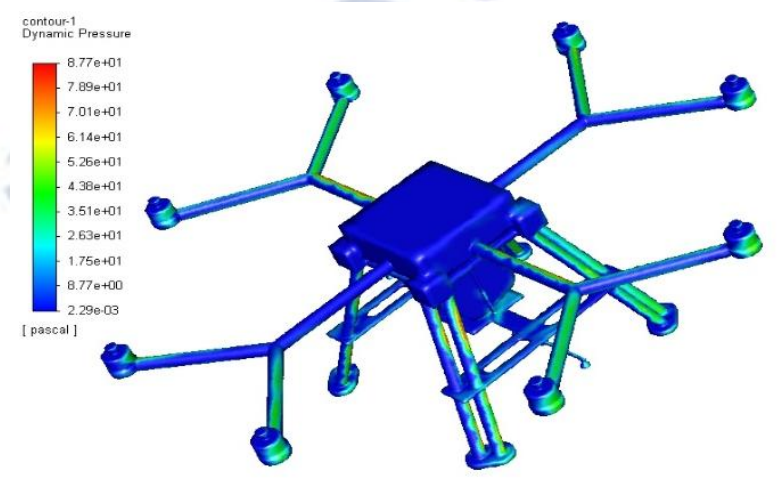

Fig 7. 2 Dynamic Pressure 


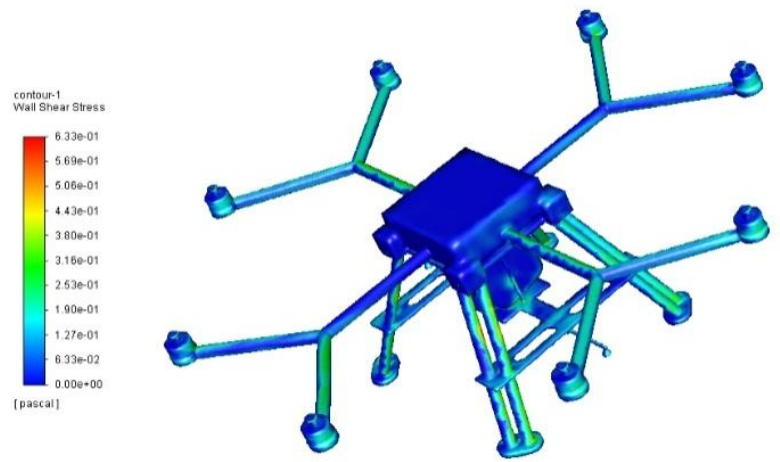

Fig 7. 3 Wall Shear Stress

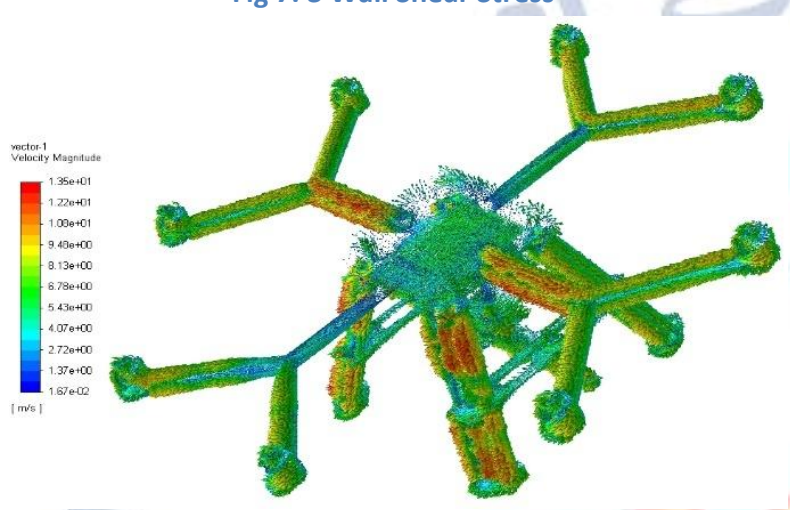

Fig 7. 4 Velocity Magnitude

\section{IMPACT ANALYSIS}

The impact analysis was done in order to identify the effect of fall of drone. In ANSYS 19.2 Explicit Dynamics the drone was made to fall from the height of $1500 \mathrm{~mm}$ (height of operation) and the simulation recorded the results for end time 0.007 $\mathrm{s}$ and the cycle of 107. After the analysis the maximum deformation and stresses were found to be induced in the region connecting motor and propeller. The motor and propeller connection are usually made up of metal and highly resilient to impact from fall and dash. The drone assembly is found to safe under the impact.

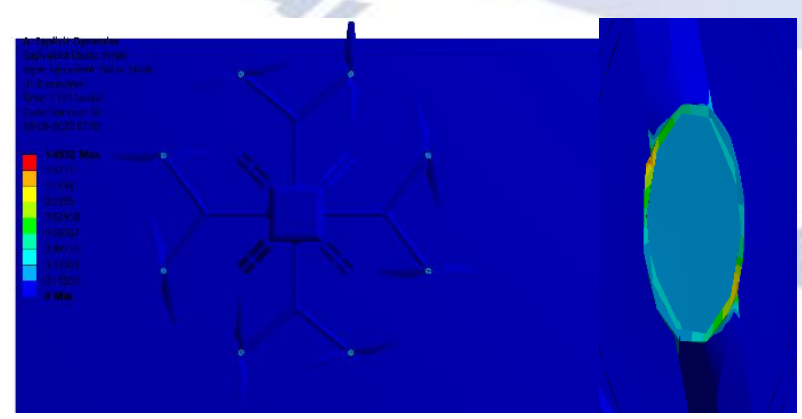

Fig 8.1 Equivalent Strain

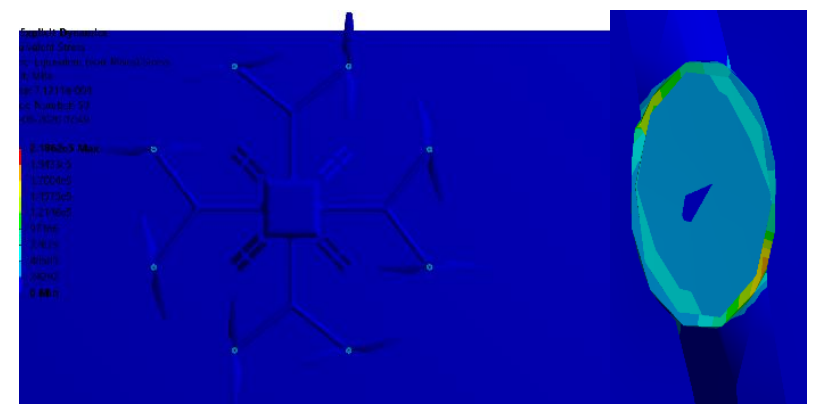

Fig 8.2 Equivalent Stress

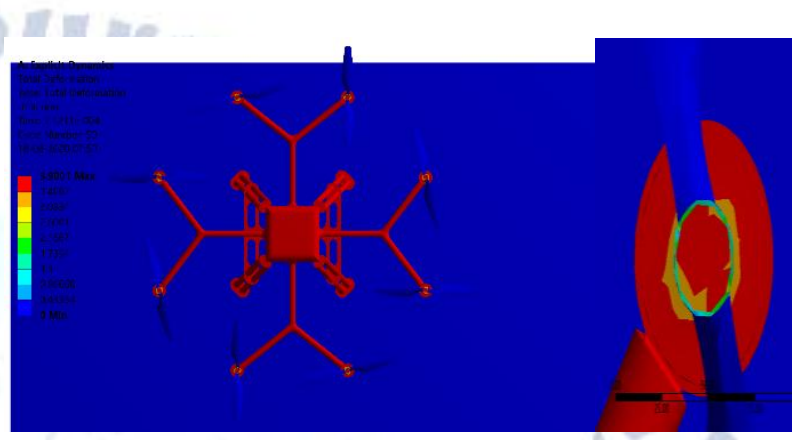

Fig 8.3 Total Deformation

Table 8.1 Impact Analysis

\begin{tabular}{|l|l|l|}
\hline \multirow{2}{*}{$\begin{array}{l}\text { Equivalent Elastic } \\
\text { Strain }\end{array}$} & Min & 0 \\
\cline { 2 - 3 } & Max & 1.4932 \\
\cline { 2 - 3 } & Avg & $7.3131 \mathrm{e}-03$ \\
\hline \multirow{2}{*}{$\begin{array}{l}\text { Squivalent Elastic } \\
\text { Stress }\end{array}$} & Min & 0 \\
\cline { 2 - 3 } & Max & $2.1862 \mathrm{e} 05$ \\
\cline { 2 - 3 } & Avg & 990.49 \\
\hline \multirow{3}{*}{ Total Deformation } & Min & 0 \\
\cline { 2 - 3 } & Max & 3.9001 \\
\cline { 2 - 3 } & Avg & 3.2403 \\
\hline
\end{tabular}

\section{Conclusion}

The following conclusions can be drawn from the analysis conducted in the paper:

1. The solid circular section provides the structural benefits along with the aerodynamic benefits.

2. The drone is found to be safe under structural , CFD and Impact Analysis and can be used for heavier payloads.

3. The Hextow IM7 embedded epoxy composite being low density as $1780 \mathrm{~kg} / \mathrm{m} 3$ is advantageous being almost $1000 \mathrm{~kg} / \mathrm{m} 3$ less than Aluminium.

4. The selection of components is a crucial process and 3:1 thrust to weight ratio provides the user with future upgrades with minimum changes. 
Appendix

\section{- T-motor V605 KV210 Motor}

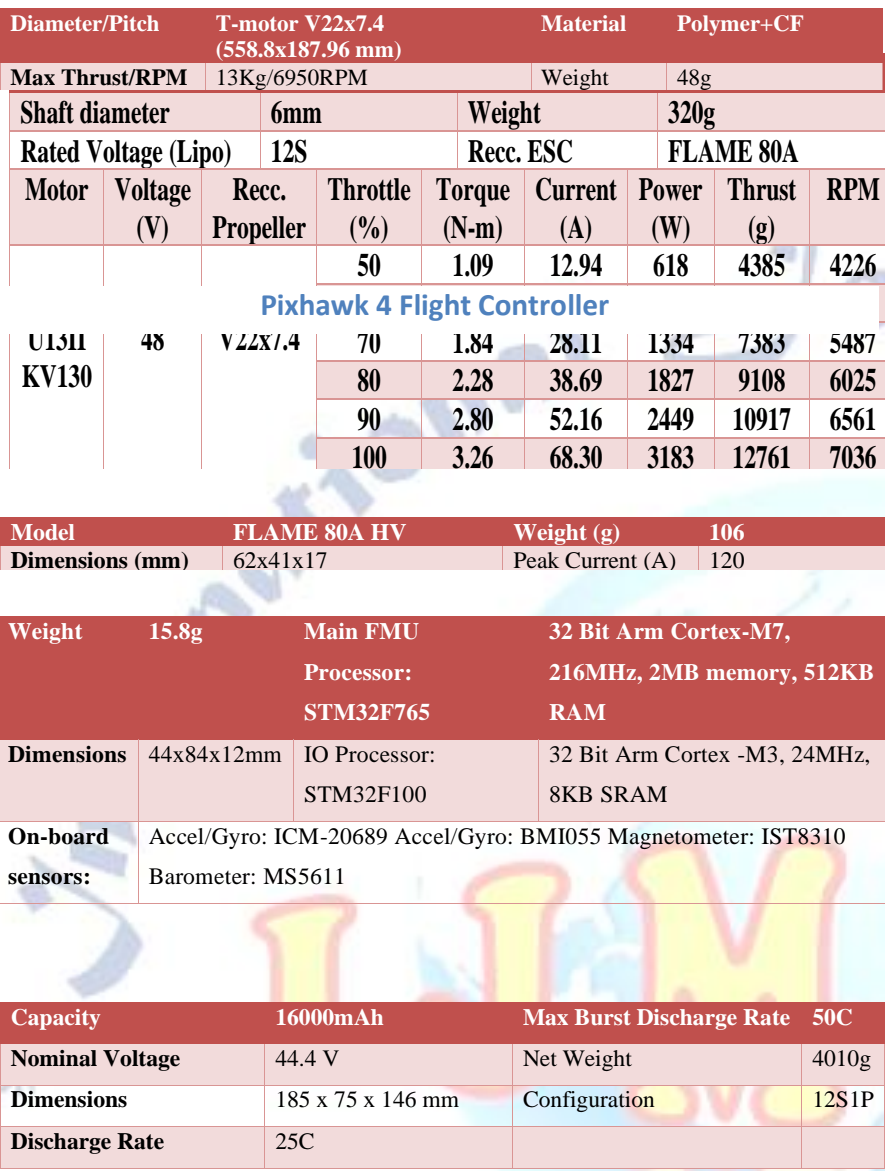

Radiolink SUI04 Ultrasonic Sensor

\begin{tabular}{l|lll} 
Model & Radiolink SUI04 & Accuracy & $0.4 \mathrm{~m}$ \\
\hline Dimensions & $5.08 \times 3.43$ x 0.51 inches & Response & $30 \mathrm{~ms}$
\end{tabular}

ublox Neo-M8N GPS/GLONASS receiver; integrated magnetometer IST8310

\begin{tabular}{|c|c|c|c|}
\hline Model & NEO-M8 & Weight (g) & 125 \\
\hline Dimensions & $12.2 \times 16 \times 2.4 \mathrm{~mm}$ & Maximum speed & $515 \mathrm{~m} / \mathrm{s}$ \\
\hline \multicolumn{4}{|c|}{$\begin{array}{c}\text { SEAFLO } 21 \text { Series DC Diaphragm Pump 12V/24V 2.0-4.3LPM } \\
\text { 17-80PSI }\end{array}$} \\
\hline \multicolumn{4}{|c|}{$\begin{array}{l}2 \text { Chamber positive displacement diaphragm pump, self-priming, capable of being } \\
\text { run dry }\end{array}$} \\
\hline Dimensions & $18.3 \times 10.6 \times 6.5 \mathrm{~cm}$ & $\begin{array}{l}\text { Priming } \\
\text { Capabilities }\end{array}$ & $\begin{array}{l}4 \text { feet }(1.2 \mathrm{~m}) \\
\text { suction lift }\end{array}$ \\
\hline Weight & $600 \mathrm{~g}$ & Max.Amp Draw & $4.0 \mathrm{~A}$ \\
\hline
\end{tabular}

Teejet Al Turbo Twinjet AITTJ60-11015

\begin{tabular}{|l|l|l|l|}
\hline Target Pressure & $\mathbf{2}$ bar & Droplet Size & \multicolumn{1}{|l|}{ Ultra-Coarse } \\
\hline Flow rate & $4.19-8.37$ 1/min & Spray Pattern & Twin Tapered \\
\hline $\begin{array}{l}\text { Weight } \\
\text { Air induction with dual } \mathbf{1 1 0} \\
\text { patterns }\end{array}$ & flat fan & Material & Polymer \\
\hline $\begin{array}{l}\text { Tip Cap Assembly } \\
\text { Tipsure ranges from 20-90 PSI (1.5-6 bar) }\end{array}$ & AITTJ60-11015VP-CE & Cap/Gasket & 114502-13-CELR \\
\hline
\end{tabular}

\section{REFERENCES}

[1]Wen, S., Han, J., Ning, Z., Lan, Y., Yin, X., Zhang, J., \& Ge, Y. (2019). Numerical analysis and validation of spray distributions disturbed by quad-rotor drone wake at different flight speeds. Computers and Electronics in Agriculture, 166, doi:10.1016/j.compag.2019.105036

[2]Yallappa, D., Veerangouda, M., Maski, D., Palled, V., \& Bheemanna, M. (2017). Development and evaluation of drone mounted sprayer for pesticide applications to crops. 2017 IEEE Global Humanitarian Technology Conference (GHTC). doi:10.1109/ghtc.2017.8239330

[3]P, V. S. R., \& Gorantla, S. R. (2019). Design and Modelling of anAffordable UAV Based Pesticide Sprayer in Agriculture Applications. 2019 Fifth International Conference on Electrical Energy Systems (ICEES). doi:10.1109/icees.2019.8719237

[4] Vihari, M. M., Nelakuditi, U. R., \& Teja, M. P. (2018). IoT based Unmanned Aerial Vehicle system for Agriculture applications. 2018 International Conference on Smart Systems and Inventive Technology (ICSSIT). doi:10.1109/icssit.2018.874879

[5] I. D. Pharne et al "Agriculture Drone Sprayer", International Journal of Recent Trends in Engineering \& Research (IJRTER) Volume 04, Issue 03; March- 2018

[6] Karan Kumar Shaw , Vimalkumar R. "Design and Development of a Drone for Spraying Pesticides, Fertilizers and Disinfectants" International Journal of Engineering Research \& Technology (IJERT) Vol. 9 Issue 05, May-2020

[7] Rahul Desale et al, "Unmanned Aerial Vehicle For Pesticides Spraying”, IJSART - Volume 5 Issue 4 - APRIL 2019

[8] Vikrant Krishna Suryawanshi et al "Design \& Development of Agricultural Fertilizer Spraying Drone with Remote Controller and Autonomous Control with low weight Aluminium Alloy frame Structure." Journal of Remote Sensing GIS \& Technology Volume 5 Issue 2 DOI: http://doi.org/10.5281/zenodo. 2631047

[9] Boguslawa Berner et al," Estimation of liquid deposition on corn plants sprayed from a drone "Mendel Net 7-8 November 2018

[10] Weicai Qin et al "Droplet deposition and efficiency of fungicides sprayed with small UAV against wheat powdery mildew" Int J Agric \& Biol Eng, Vol. 11 No.2 pg. 27

[11] S.Meivel M.E. et al," Quadcopter UAV Based Fertilizer and Pesticide Spraying System" International Academic Research Journal of Engineering Sciences Vol. no. 1 issue no 1, February 2016, Page No.8-12

[12] Dr.R.Athilingam et al , " Design and Development of a Drone for multiple applications", 1st International Conference on New Scientific Creations in Engineering and Technology (ICNSCET-19) International Journal of Recent Trends in Engineering \& Research (IJRTER) Special Issue; March - 2019 [ISSN: 2455-1457].

[13] Parthasarathy Garre and Alladi Harish et al," Autonomous Agricultural Pesticide Spraying UAV" Materials Science $\begin{array}{llll}\text { and Engineerintag } 455 \quad(2018) & 012030\end{array}$ doi:10.1088/1757-899X/455/1/012030

[14] Koerber, H., Xavier, J., \& Camanho, P. P. (2010). High strain rate characterisation of unidirectional carbon-epoxy IM7-8552 in transverse compression and in-plane shear using digital image correlation. Mechanics of Materials, 42(11), 1004-1019. doi:10.1016/j.mechmat.2010.09.003

[15] Hexcel Corporation, "HexTow IM7 Carbon fiber" Hexcel Product Data Sheet 2020 https://www.hexcel.com/user_area/content_media/raw/I M7_HexTow_DataSheet.pdf 